\title{
Sailing into Wind Is Explained by Newtonian Mechanics Based on The Mass-Flow Rate
}

\author{
N. Landell-Mills
}

\section{ABSTRACT}

The physics of sailing into the wind can be explained using Newtonian mechanics based on the mass flow rate. The sail re-directs a mass of air each second $(\mathrm{m} / \mathrm{dt})$ towards the boat's stern, at a relative velocity (dv) that depends on the apparent wind. The re-directed airflows push against the otherwise undisturbed apparent wind to create a backward force (i.e. Force $=\mathrm{ma}=\mathrm{m} / \mathrm{dt} \times \mathbf{d v})$. The reaction generates an equal and opposite forward force that pushes the boat ahead.
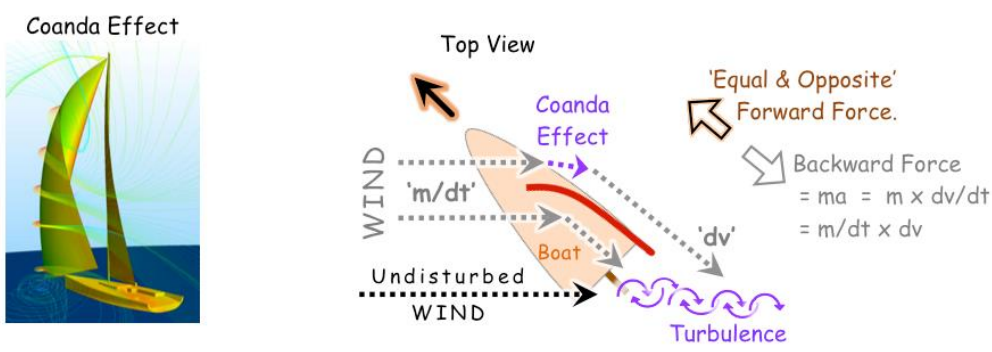

There are two separate airflows as the sail re-directs the wind on the sail's windward and leeward sides. The leeward airflow relies on the Coanda effect and is sensitive to the sail's angle-of-attack (AOA).

This approach provides new and valuable insights on sailing into the wind. However, it is a very different approach compared to the current explanations of sailing into the wind, described by fluid mechanics and vector-based solutions.

Keywords: Coanda effect, Newton, physics, sailing.

Published Online: August 31, 2020

ISSN: $2684-4451$

DOI :10.24018/ejphysics.2020.2.4.18

N. Landell-Mills *

Independent researcher.

(e-mail: nicklm@ gmx.com)

*Corresponding Author

\section{INTRODUCTION}

\section{A. The physics of sailing into the wind is disputed}

The physics behind how boats sail into the wind is unresolved. There is no agreed upon theory or equation that explains the creation of the forward force on a sail. No experiments on real sailboats in realistic conditions have been conducted to prove any of the current theories to be true. Many academics mistake mathematical proof (e.g. Navier-Stokes) or computer simulations (e.g. CFD) for scientific proof. The argument for sailing into the wind is tied directly to the debate of how an airplane's wing generates lift.

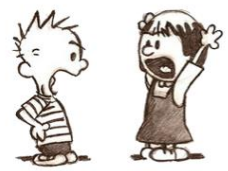

Fig. 1. Physics disputed.
Current explanations of sailing involve complex mathematics, which broadly fall into two groups:

- Fluid mechanics that explains how airflow on the sail pulls (sucks) the boat forward due to low air pressure in front of the sails [3], [4];

- Vector-based solutions that explain how the forward force is created from mechanical interactions between the wind, sail, hull, keel, and water [2].

The failure to adequately explain sailing is puzzling given how long people have been sailing and how important sailpowered boats was to early global economic development.

The objective of this paper is to present a new explanation of the physics of sailing into the wind using Newtonian mechanics based on the mass flow rate.

\section{B. Benefits of the Newtonian approach}

The Newtonian approach with an understanding of the Coanda effect provides significant new insight into sailing, which solves a number of conundrums, including:

- When turning a sailboat closer into the wind, the boat's speed can increase significantly despite having less sail area exposed to the wind. 
- Why boats sail more efficiently with multiple sails, instead of a single large sail with the same total sail area.

- How a boat can sail into the wind faster than the wind itself, but cannot sail with the wind at a speed that is faster than the wind.

Additional benefits of the Newtonian approach include:

- A simple and easily understood explanation of sailing that is consistent with standard physics equations.

- A method to accurately calculate the forces, kinetic energy, and power generated by the sail.

- This approach is consistent with how an airplane's wings generate lift [12].

\section{A significant technological development}

The Portuguese were considered to be the first to perfect sailing into the wind in the 15 th century, with sailboats such as the Caravel. See Fig. 2.

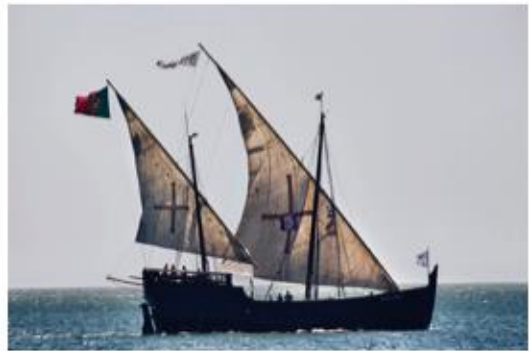

Fig. 2. Portuguese Caravel [8].

Previously, sea travel was limited to coastal areas. This technology was a pivotal development as it permitted the Portuguese to sail against the prevailing winds and across oceans with reduced travel times. Sea travel became significantly cheaper and faster. In turn, it allowed the Portuguese to develop an empire based on trading relations with the more distant parts of the world, such as spice trade with the Indies, before the rest of Europe [6]. See Fig. 3.

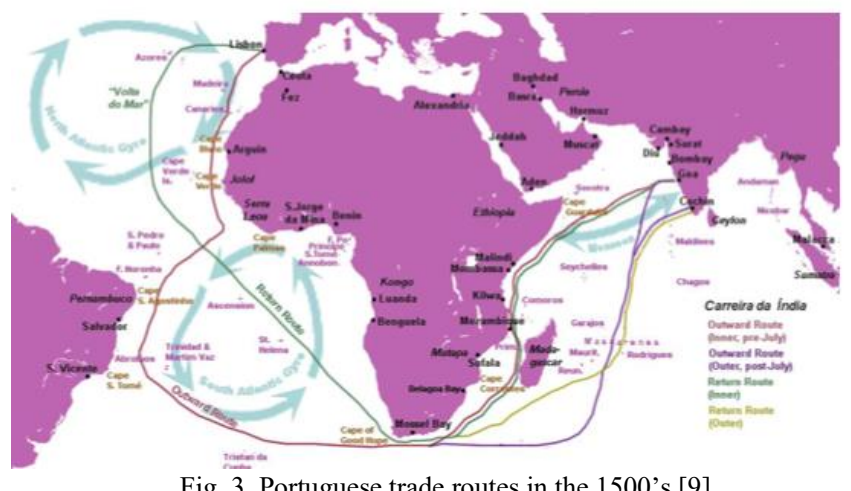

Fig. 3. Portuguese trade routes in the 1500's [9].

As this new sailing technology spread, it permitted other European countries to explore, trade, and colonize the rest of the world. Without this technology, the global economy and politics would have evolved very differently.

\section{SAILING INTO WIND - SUMMARY}

\section{A. Newtonian mechanics explains sailing}

The forward force generated by a sailboat depends primarily on the amount and speed of air re-directed by the sail. Boats sailing into the wind on a close haul tack at a low sail AOA, re-direct a mass of air each second $(\mathrm{m} / \mathrm{dt})$ backwards at a velocity relative to the boat $(\mathrm{dv})$. This action creates a backwards force (i.e. Force $=m a=m / d t \times d v)$ as it pushes against the undisturbed air from the apparent wind. The reaction generates an equal and opposite forward force that pushes the boat ahead. See Fig. 4.

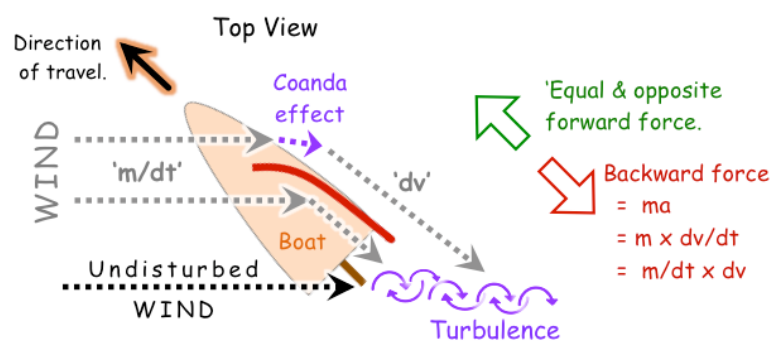

Fig. 4. Newtonian forces on a sailboat.

Fluid flow (airflow) naturally follows a curved surface due to the Coanda effect. For example, water falling from a tap is re-directed by a spoon in Fig. 5. The Coanda effect enhances both ' $\mathrm{m} / \mathrm{dt}$ ' as well as ' $\mathrm{dv}$ ' in the airflow on the leeward side of the sail.

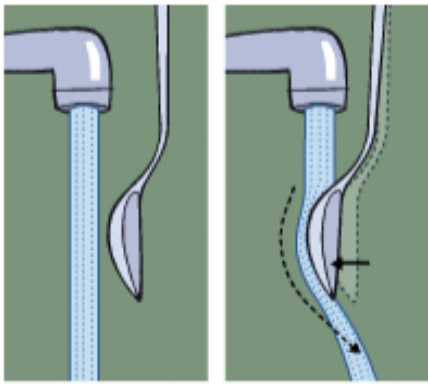

Fig. 5. Falling water re-directed by a spoon

\section{B. Example calculation}

An example calculation assumes that a $12 \mathrm{~m}$ high sail redirects the wind $0.5 \mathrm{~m}$ on either side of the sail $(1.0 \mathrm{~m}$ in total). See Fig 6.
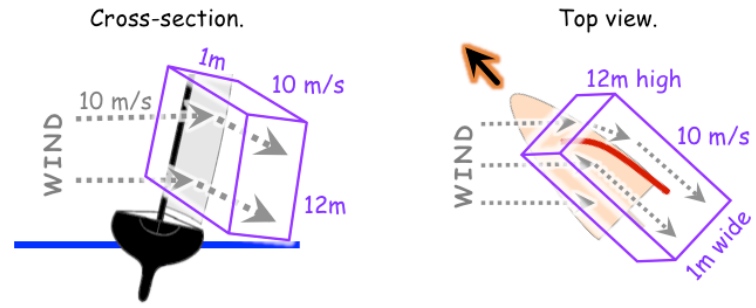

Fig. 6. Volume of air displaced by a sail.

It is assumed that the apparent wind is blowing at $10 \mathrm{~m} / \mathrm{s}$, and the air density is $1.2 \mathrm{~kg} / \mathrm{m}^{3}$. 
This sail displaces a volume of $120 \mathrm{~m}^{3}$ or a mass of $144 \mathrm{~kg} / \mathrm{s}$ of air $(\mathrm{m} / \mathrm{dt})$. If the wind were re-directed by the sail at $8 \mathrm{~m} / \mathrm{s}(\mathrm{dv})$, then according to Newtonian mechanics this would create a backward force of $1,152 \mathrm{~N}$. The reaction generates a forward force of 1,152 N. See Fig. 7.

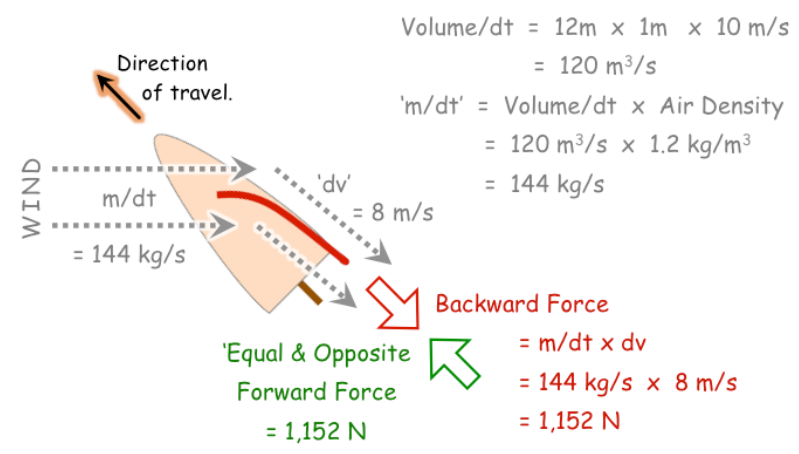

Fig. 7. Example calculation of Newtonian forces.

This example calculation shows how simple the forces involved are in principle. However, it may be difficult to measure ' $\mathrm{m} / \mathrm{dt}$ ' and ' $\mathrm{dv}$ ' accurately.

\section{Relative speeds}

Sailboats can sail into the wind faster than the wind itself. For example, a sailboat sailing at $12 \mathrm{~km} / \mathrm{hr}$ on close haul into a $10 \mathrm{~km} / \mathrm{hr}$ wind, could be travelling at $20 \mathrm{~km} / \mathrm{hr}$ relative to the wind. See Fig. 8.
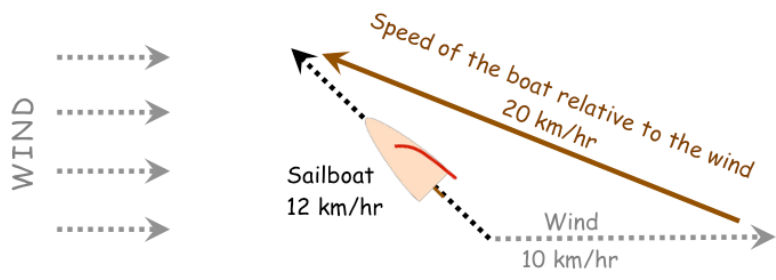

Fig. 8. Illustration of relative speeds.

\section{Sailing into the wind}

When sailing closer into the wind with a lower sail AOA, a boat's speed can increase significantly and up to several multiples of the wind's speed.

According to Newtonian mechanics (i.e. Force $=\mathrm{m} / \mathrm{dt} \times$ $\mathrm{dv}$ ), the closer the boat sails into the wind, the greater the ' $\mathrm{m} / \mathrm{dt}$ ' and ' $\mathrm{dv}$.' In turn this creates greater backward and forward forces. More precisely:

i. The Coanda effect is highly sensitive to the sail's AOA. On a close haul tack, there is less turbulence and airflow separation on the leeward part of the sail. See Fig. 9.

ii. At a lower sail AOA, the apparent wind is deflected at a lower angle, therefore, it loses less of its force, as compared to a beam reach. In turn, this effect minimizes the sideways force and maximizes ' $\mathrm{dv}$ ' on a close haul.
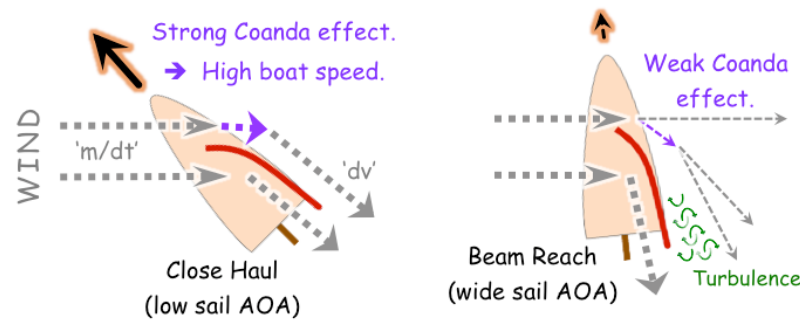

Fig. 9. Coanda effect is stronger on a close haul

iii. The dynamics of this process create a positive feedback loop. As the boat sails faster into the wind, it increases the mass of air sailed through each second $(\mathrm{m} / \mathrm{dt})$, which further increases the forward force created.

iv. The sailboat heels (tilts) less and moves more efficiently through the water with less drag.

v. In short, turning a sail closer into the wind is similar to pressing down on the accelerator of a car. The sail is more efficient at creating a forward force as it re-directs a greater mass of air each second $(\mathrm{m} / \mathrm{dt})$ at a higher relative velocity (dv).

\section{E. Sailing into the wind $v$. with the wind}

A nautical conundrum exists: A sailboat on a close haul can sail into the wind faster than the wind itself, but a boat sailing with the wind cannot sail faster than the wind. For example, a boat can sail at $20 \mathrm{~km} / \mathrm{hr}$ into a $10 \mathrm{~km} / \mathrm{hr}$ wind, but not faster than $10 \mathrm{~km} / \mathrm{hr}$ with the wind. See Fig. 10 .
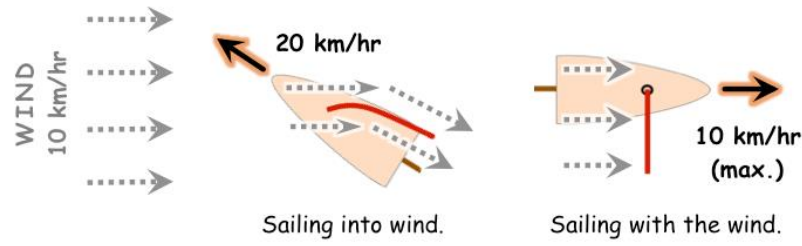

Fig. 10. Example of sailing speeds relative to the wind.

This is a conundrum for several reasons:

- At first glance it appears illogical for a boat to be able to sail into the wind, and to do so faster than the wind. Surely, the wind should blow the boat in the direction of the wind. How then does the sailboat use the wind to create a forward force in the opposite direction to the wind, which is greater than the wind itself?

- Compared to running with the wind, on a close haul, relatively little sail is exposed to the wind. Surely, the sail would generate less power.

Newtonian mechanics and the Coanda effect provide a simple solution to this conundrum.

i. When sailing into the wind, a significantly greater airflow (m/dt) is re-directed due to the Coanda effect on the leeward side of the sail at a higher velocity (dv).

ii. When running with the wind, the sail has nothing to push against and cannot re-direct the wind. Therefore, no 'equal and opposite force is possible. The boat's speed is then limited to the speed of the wind. In addition, no Coanda effect is possible on the leeward part of the sail, limiting the amount of wind being re-directed. Only the windward side 
of the sail is providing any forward force. See Fig. 11.
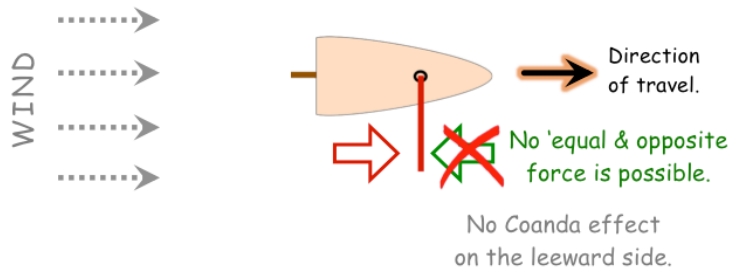

Fig. 11. Sailing with the wind.

\section{F. Multiple sails}

This Newtonian approach can explain why multiple sails (e.g. jib and mainsheet) provide a greater forward force than a single, large sail with the same total sail area. Specifically, multiple sails increase the mass flow rate $(\mathrm{m} / \mathrm{dt})$ without significantly jeopardizing the relative acceleration of air (dv).

A higher ' $\mathrm{m} / \mathrm{dt}$ ' then increases the overall force generated using the Newtonian equation: Force $=m a=m / d t x d v$. See Fig. 12 and Fig. 13.
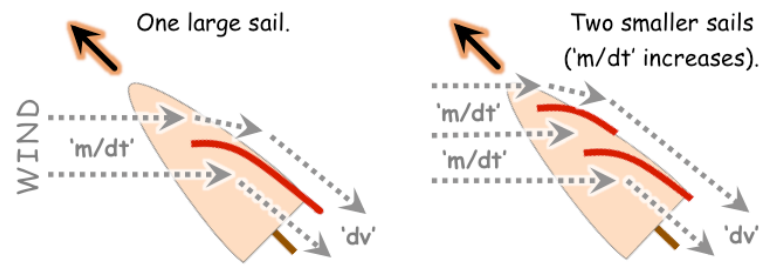

Fig. 12. One large sail v. two smaller sails with the same total sail area.
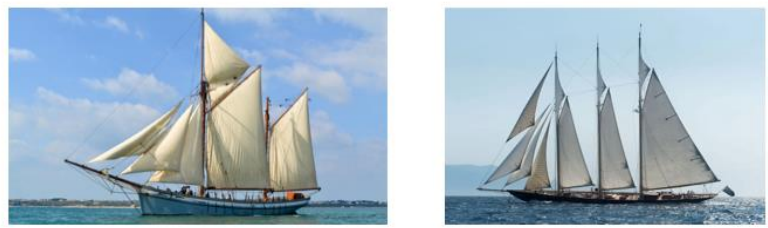

Fig. 13. Boats with multiple sails [10].

\section{BACKGROUND - SAILING BASICS}

For clarity, the basics of sailing relevant to this paper are outlined below.

\section{A. The basics of sailing}

The sail AOA is the angle between the sail's direction and the apparent wind. This is different to the boat's AOA, which is the angle between the boat's heading and the apparent wind. See Fig. 14.

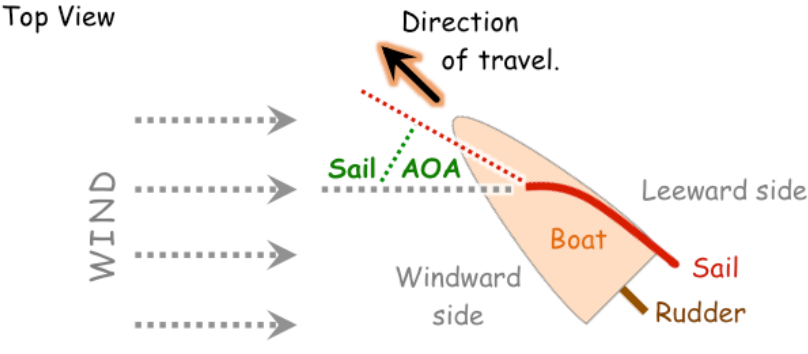

Fig. 14. Sailing basics.

The primary functions of the key controls include:

- $\quad$ The sail provides the power for the boat.

- The rudder controls the direction of the boat.

- $\quad$ The keel provides stability, by preventing the boat from being tipped over and pushed downwind.

To move forward, the force generated by the sail must be sufficient to overcome the drag from the water and any drift due to the water current. Drag is the force required to push the water out of the boat's path due to the inertia from the water.

A boat's direction relative to the wind has the terms shown in Fig. 15.

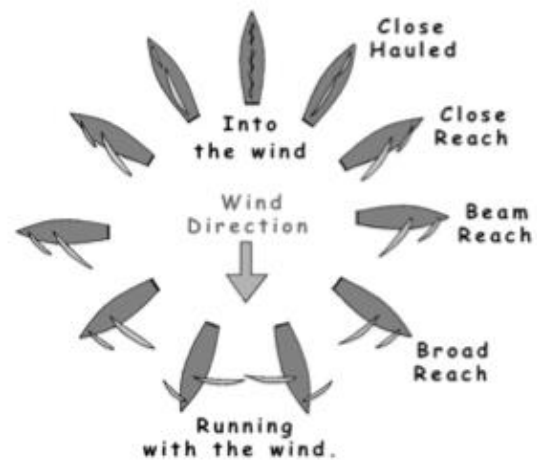

Fig. 15. Points of sail

For a boat sailing into the wind, apparent wind speed is the wind measured relative to the boat. Apparent wind speed can be quite different from true wind speed, as experienced by a stationary observer.

The two forces on a sail

On a close haul tack into the wind, the wind creates two separate forces as it hits the sail (See Fig. 16):

i. The wind re-directed backwards by the sail, creates a backward force by pushing against the undisturbed wind.

ii. The wind exerts a smaller direct sideways force on the sail, which causes the boat to tilt, pushing the keel sideways.

iii.
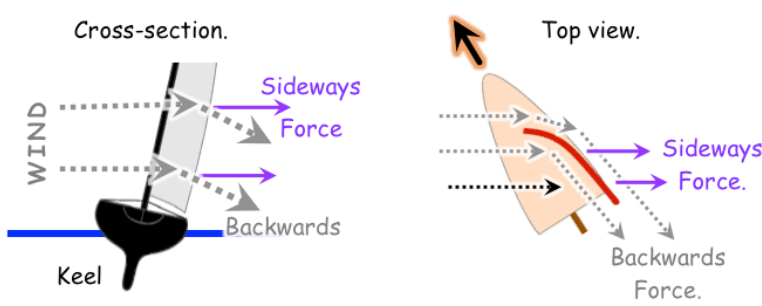

Fig. 16. Two forces on a sail on a close haul tack. 
On a close haul tack into the wind, the sail re-directs most of the wind's momentum and energy backwards. Only a relatively small force is applied sideways on the sail.

These two forces are shown separately in Fig. 17.
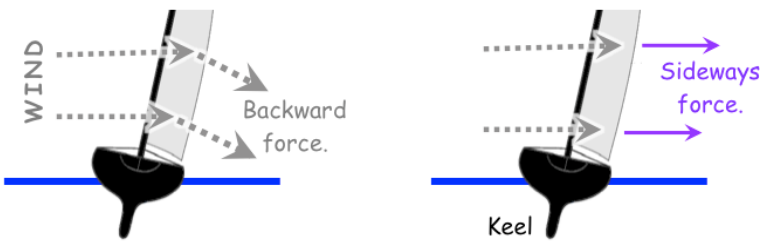

Fig. 17. Two forces on a sail shown separately.

\section{B. The sideways force}

The sideways force is resisted by the boat's hull and keel:

i. The resistance from the hull and keel limits the amount of drift and prevents the boat from being blown in the same direction as the wind. See Fig. 18.

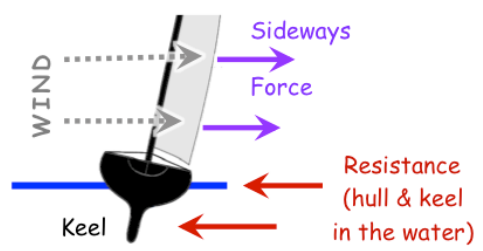

Fig. 18. Resistance from the hull and keel.

ii. The resistance from the keel prevents sailboats from tilting and tipping over. The weight of the keel also helps to keep the center of mass lower and close to the water level. See Fig. 19

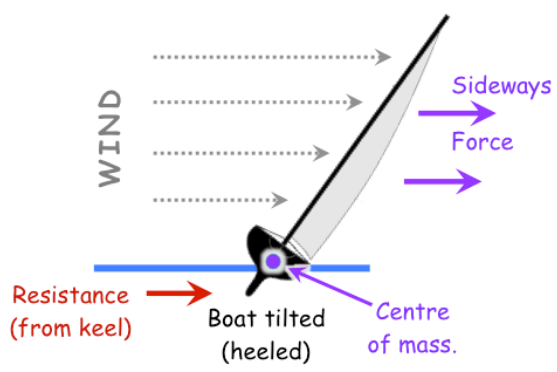

Fig. 19. Resistance from the keel against tilt.

\section{Catamarans do not need a keel}

Catamarans sailing into the wind without a keel demonstrate that the keel is not always required to oppose the sideways force. Instead, two separate hulls are used to prevent the boat from tipping over, and to provide resistance to the sideways force, for two reasons:

i. The leeward hull in the water itself provides resistance to the sideways force, preventing the catamaran from being pushed downwind, similar to a boat with a keel.

ii. The 2nd hull that is out of the water on the windward side provides balance and prevents the boat from tipping over. The hull in the water acts as a pivot against the sideways force. This replicates the benefits of a keel. See
Fig. 20 and Fig. 21.
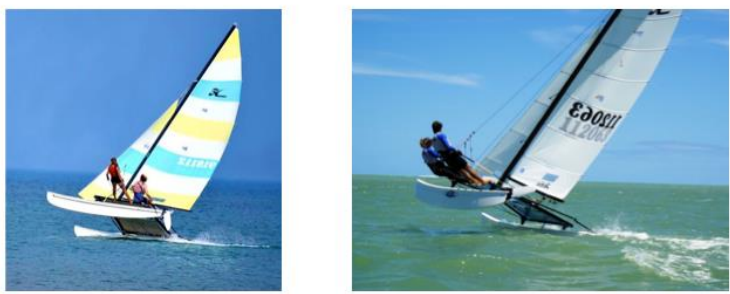

Fig. 20. Catamarans sailing into the wind.

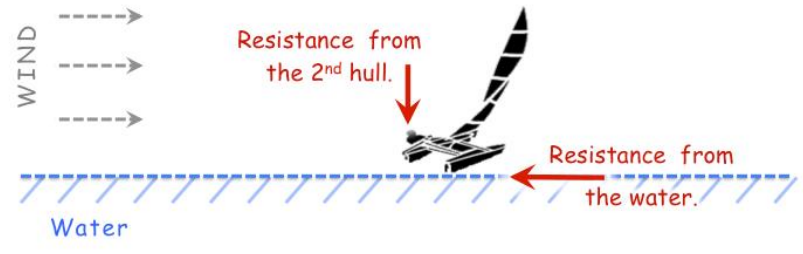

Fig. 21. The forces on a catamaran sailing into the wind

\section{BACKGROUND - AIRFLOW ANALYSIS}

\section{A. Two sail airflows}

There are two key airflows created by the sail, one on the windward side of the sail and one on the leeward side. See Fig. 22.

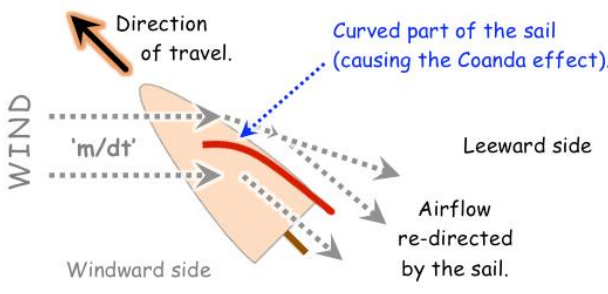

Fig. 22. Wind re-directed by the sail.

The airflow re-directed by the windward and leeward sides of the sail can be analyzed separately:

i. On the windward side of the sail, the sail acts as a physical obstacle and pushes the wind in a given direction, which creates high air pressure. A barrier that re-directs the airflow from a fan illustrates this point. The ball behind the barrier is blown in the same direction as the re-directed airflow. See Fig. 23.

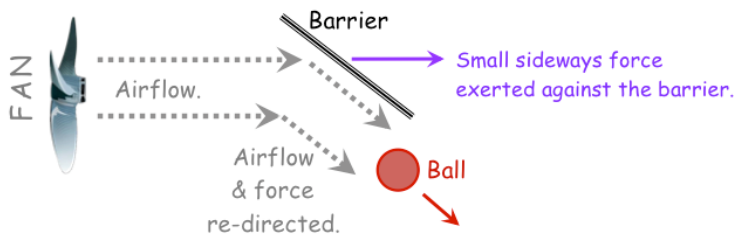

Fig. 23. Airflow re-directed by a barrier.

ii. On the leeward side of the sail, the curved (bowed or concaved) surface of the sail re-directs wind due to the Coanda effect. This boosts the total ' $\mathrm{m} / \mathrm{dt}$ ' and ' $\mathrm{dv}$ ' of the re-directed airflow. In turn, this increases the forces generated by the sail. The sail is effectively pulling the air around the sail, bending its direction. This creates low pressure on the leeward side of the sail. See Fig. 24. 


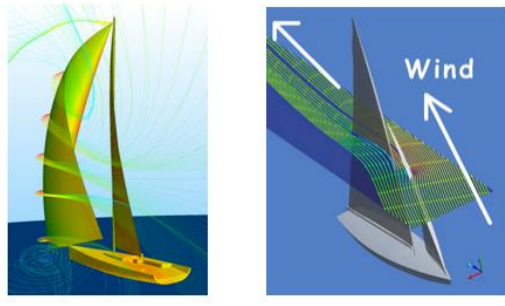

Fig. 24. Simulation of the Coanda effect on sails.

\section{B. Airflow turbulence}

To generate the greatest possible force in the direction of travel, the sail maintains laminar (smooth) airflow. Any airflow over the sail that becomes disrupted causes turbulence, which reduces ' $\mathrm{m} / \mathrm{dt}$ ' and ' $\mathrm{dv}$ ' of the re-directed airflow, and the sail loses power. This typically occurs when the sail has a sub-optimal AOA for the wind conditions, heading, and sail shape.

Laminar airflow is associated with the sails generating the maximum forward force possible. Whereas turbulence and airflow separation are associated with the loss of forward force generated by the sail.

There is a lack of videos and photographs available of sails that illustrate these points. However, wind tunnel experiments with smoke blown over airplane wings can be used to demonstrate the laminar and turbulent airflows (see Fig. 25).
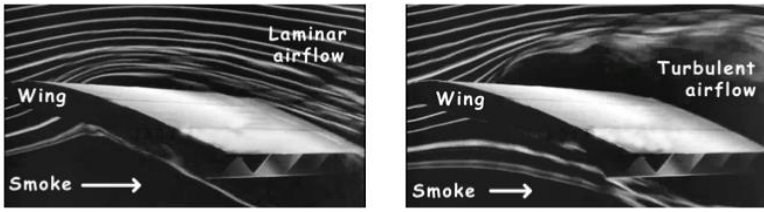

Fig. 25. Laminar and turbulent airflows over a wing [1].

\section{Telltales}

Telltales are small pieces of string attached to both sides of a sail. See Fig. 26.
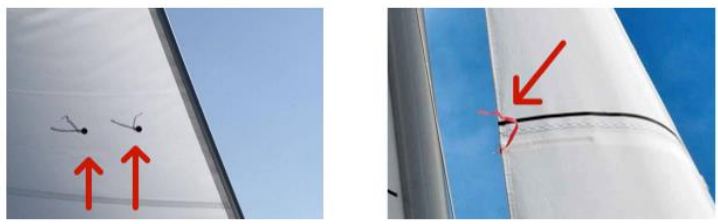

Fig. 26. Telltales on a sail.

Sailors use telltales as airflow indicators to judge what type of airflow is being maintained on the different parts of the sails. This helps assess how well the sail is aligned to the optimum sail AOA under the prevailing conditions. In short, telltales provide evidence that the sails are re-directing the air as desired.

The equivalent to a telltale on an airplane wing is a stall indicator, which measures when airflow across the wing is being disrupted sufficiently to generate a stall.

For example, disrupted telltales on the leeward sail indicate turbulent airflow. Reducing the sail AOA could establish laminar airflow and remove the turbulence. This is similar to an airplane wing that has a high AOA and turbulent airflow on the topside of the wing. A typical aviation solution to reduce the turbulent airflow is to reduce the wing AOA by lowering the nose of the airplane.

\section{The Coanda effect}

Fluid flow (airflow) naturally follows a curved surface due to the Coanda effect. This is shown by how water falling from a tap is re-directed by a spoon in Fig. 5.

The sail re-directs the air flowing around the curved (cambered or convex) leeward side of the sail due to the Coanda effect. A stronger Coanda effect maximizes the mass of air displaced each second $(\mathrm{m} / \mathrm{dt})$ and thus the generated forces.

Wind tunnel experiments with smoke blown over airplane wings demonstrate the Coanda effect (see Fig. 27).
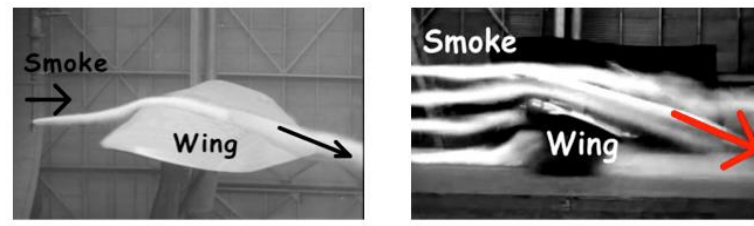

Fig. 27. Coanda effect on wings in wind tunnels [1].

In general, a stronger Coanda effect arises at a lower AOA and higher airflow velocities.

\section{E. Sailboat tilt}

The tilt of a sailboat affects the sail airflows, but it does not affect the amount of wind that the sail passes through. For example, a $12 \mathrm{~m}$ tall mast will have $12 \mathrm{~m}$ exposed to the wind regardless of the boat's tilt. However, tilt can also be important if the wind velocity varies with altitude (height above the water). See Fig. 28.
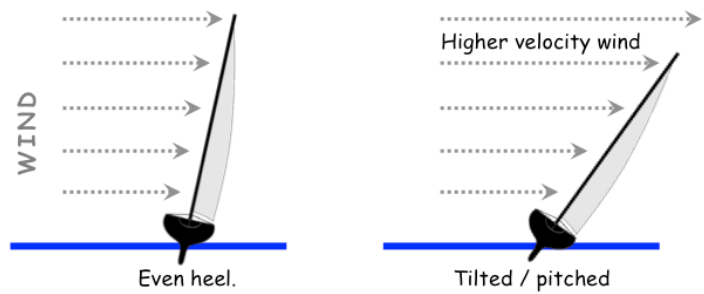

Fig. 28. Sailboat on an even heel and tilted.

\section{NEWTON EXPLAINS SAILING}

\section{A. Newtonian mechanics sailing}

The physics of sailing into the wind is straightforward. Most of the force in the wind is re-directed by the sail towards the stern (back) of the boat. This re-directed airflow collides with the undisturbed apparent wind, providing something to push against, which creates turbulence.

The mass of wind re-directed by the sail each second $(\mathrm{m} / \mathrm{dt})$ and its relative velocity $(\mathrm{dv})$ vary depending on the sail size, AOA, shape, height and width, as well as apparent wind speed. See Fig 29. 


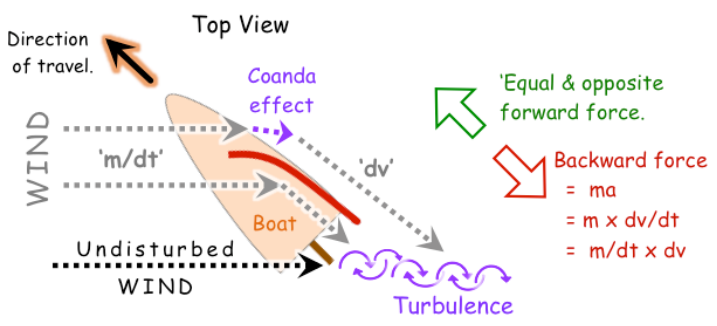

Fig. 29. Newtonian forces on a sailboat.

Newtons 2nd law of motion provides the equation for the force generated:

$$
\begin{aligned}
\text { Backward Force } & =\mathrm{ma}[1] \\
& =\mathrm{m} \times \mathrm{dv} / \mathrm{dt} \\
& =\mathrm{m} / \mathrm{dt} \times \mathrm{dv}
\end{aligned}
$$

where:

$\mathrm{m}=$ Mass of air displaced (wind re-directed) by the sail. $\mathrm{m} / \mathrm{dt}=$ Mass flow rate.

$\mathrm{dv}=$ Change in velocity of the air relative to the boat.

$\mathrm{dt}=$ Change in unit time (seconds).

$\mathrm{a}=\mathrm{dv} / \mathrm{dt}=$ Acceleration of the airflow re-directed.

According to Newtons 3rd law of motion, the reaction generates an equal and opposite forward force, pushing the boat ahead:

\section{Backward Force $=$ Forward Force}

More on the speed of the re-directed airflow (dv):

- The difference between velocity of the apparent wind and ' $\mathrm{dv}$ ' represents the force, energy and momentum lost to pushing the boat sideways, friction or otherwise.

- $\quad d v$ ' is a weighted average of the ' $d v$ ' for the two airflows on the windward and leeward sides of the sail.

- $\quad$ 'dv' will vary with the distance away from the sail.

To summarize, in the Newtonian explanation of sailing:

- ' $\mathrm{m} / \mathrm{dt}$ ' primarily determines the amount of air caught by the sail.

- ' $d v '$ primarily determines the relative acceleration of this air caught by the sail.

- Sail AOA primarily determines the direction of the forces generated by the re-directed airflow.

The relationship between airflows and forces is consistent with what is observed. For example, a sailor can control the force generated by the sail through changing the AOA. This alters both the ' $\mathrm{m} / \mathrm{dt}$ ' and ' $\mathrm{dv}$,' as well as the direction the forward force is created.

\section{B. Not a momentum theory}

This explanation of the physics of sailing is similar to the momentum or flow-turning theories of sailing, but different in important ways. For example, the momentum theory of sailing focuses on the change in the momentum of the air deflected backwards: Force $=\mathrm{ma}=\mathrm{d}(\mathrm{mv}) / \mathrm{dt}$ [1]. Whereas the Newtonian approach based on the mass flow rate uses the equation: Force $=\mathrm{m} / \mathrm{dt} \times \mathrm{dv}$.

\section{Turbulence}

The diagram below provides an illustration of how turbulence arises as the airflow re-directed by the sail encounters the undisturbed oncoming wind. Turbulence allows for the creation of the backward and forward forces. See Fig. 30.

The lack of turbulence on the leeward part of the sail up to the end of the mast, allows it to displace the air backwards more effectively as compared to the windward side.

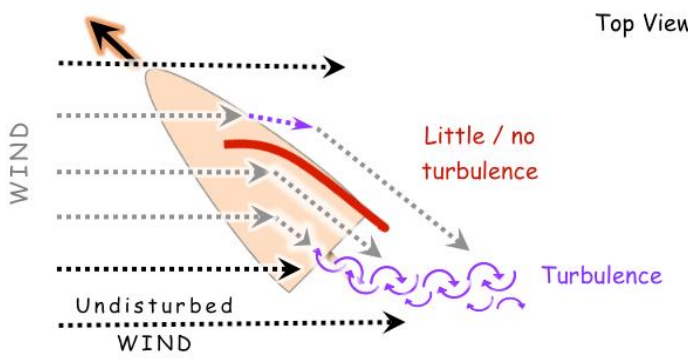

Fig. 30. Airflow turbulence around the sail.

\section{Airboat comparison}

A sail acts in a manner that is somewhat similar to a big fan or propeller that pushes air backwards on an airboat. See Fig. 31 .

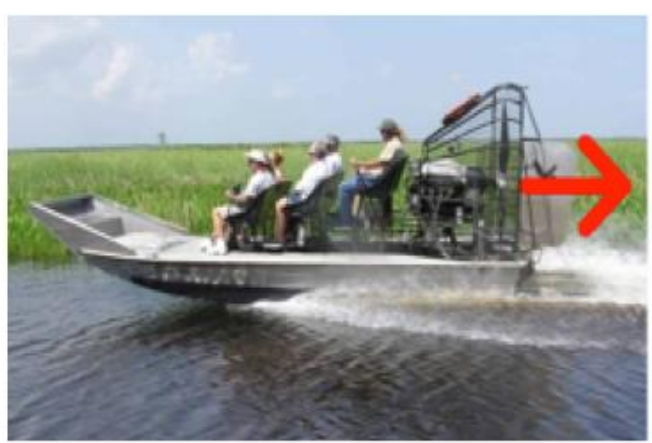

Fig. 31. Airboat.

The comparison between a sailboat and an airboat is only meant to illustrate the principles of Newtonian mechanics involved. By pushing air backwards, the airboat generates an equal and opposite forward force, which is similar to a sail that re-directs the wind. By re-directing the apparent wind, the sail is creating a force similar to a propeller. That's the limit of the comparison being made between a sailboat and an airboat.

\section{E. Relative speeds}

Sailboats can sail into the wind faster than the wind. For example, a sailboat sailing at $12 \mathrm{~km} / \mathrm{hr}$ on close haul into a $10 \mathrm{~km} / \mathrm{hr}$ wind, could be travelling at $20 \mathrm{~km} / \mathrm{hr}$ relative to the wind. See Fig. 32. 

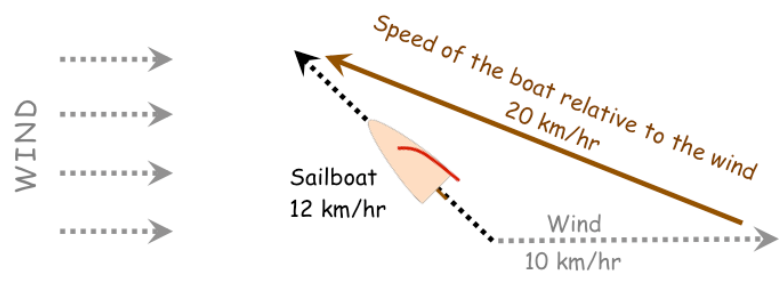

Fig. 32. Relative speeds.

\section{F. Sail reach}

To calculate the amount of air displaced by a sail it is necessary to understand the concept of sail reach. Sail reach is the horizontal distance away from the sail that the sail affects the wind. See Fig. 33.

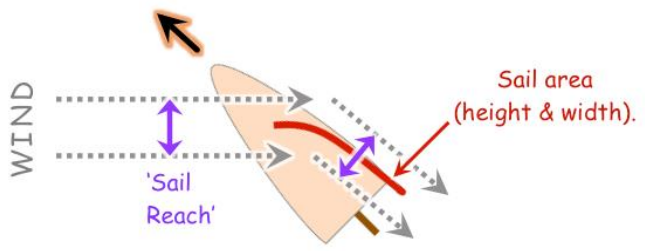

Fig. 33. Sail reach.

The sail reach depends on the sail size, height, width, shape AOA, and the Coanda effect on the leeward side of the sail.

Sail reach may not be equidistant on either side of the mast. It may be different on the windward and leeward sides.

\section{G. Sail area, height and width}

The terminology used for sail area, height, and width is illustrated in Fig. 34.

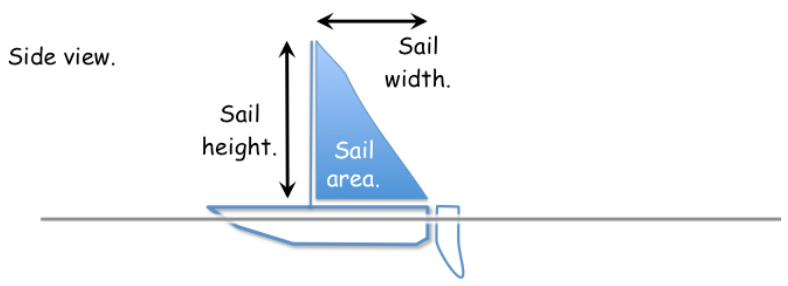

Fig. 34. Sail area, height, and width

There is no simple relationship between sail area exposed to the wind and the forward force generated by the sail. However, an analysis of sail height and width does provide a method to estimate the forward force generated by looking at how these factors affect ' $\mathrm{m} / \mathrm{dt}$ ' and ' $\mathrm{dv}$.'

In the Newtonian explanation of sailing, on a close haul into the wind:

- Sail height and sail reach primarily determines the amount of air caught by the sail (m/dt).

- Sail width primarily determines the relative acceleration of the air caught (dv).

This explains why a significant forward force can be generated on a close haul tack into wind despite relatively little of the sail area is exposed to apparent wind.

\section{H. Alternative perspectives (diagrams)}

To provide an alternative perspective, a diagram of forces acting on a sailboat is shown below with the wind from a different direction. The boat remains on a close haul tack. The forces involved also remain the same. See Fig. 35 .

Top View

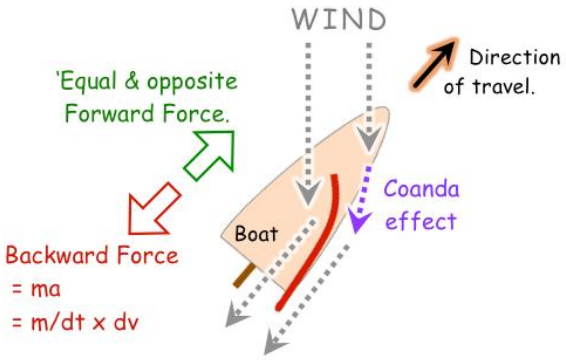

Fig. 35. Forces on a sailboat from a different perspective.

The forces and airflows on a sail can be presented to show a stationary boat relative to a moving airflow, and vice versa. In the example below, the water current (e.g. 5 knots) is exactly offsetting the forward motion of the sail (e.g. 5 knots). See the explanation below. See Fig. 36.

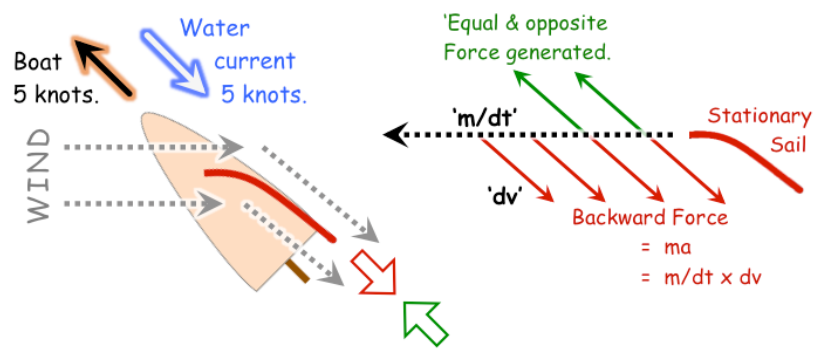

Fig. 36. Forces on a stationary sailboat, sailing into wind.

\section{NEWTON EXPLAINS SAILING INTO WIND}

\section{A. Sailing into the wind and AOA}

When sailing close into the wind, the boat's speed can increase significantly, up to several multiples of the wind's speed. This is despite having considerably less sail area directly exposed to the wind on the windward side of the sail.

As the sail AOA declines, the generated forward force increases, causing the boat's speed to also increase in a nonlinear manner. Boats sail significantly faster as the AOA declines. This occurs up to a point when the sails stall while sailing directly into the wind, and cease to generate a forward force. See Fig. 37.

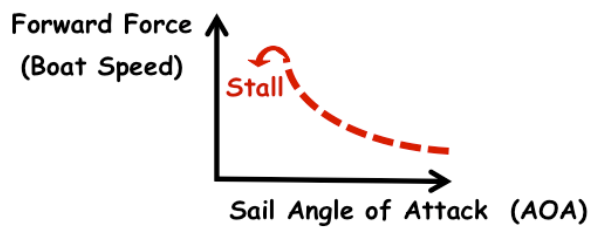

Fig. 37. Sail AOA and forward force.

According to Newtonian mechanics (i.e. Force $=\mathrm{ma}=$ $\mathrm{m} / \mathrm{dt} \times \mathrm{dv}$ ), the closer the boat sails into the wind, the greater the ' $\mathrm{m} / \mathrm{dt}$ ' and ' $\mathrm{dv}$.' Therefore, the greater the backward and forward forces created. 


\section{B. Coanda effect and AOA}

According to Newtonian mechanics, the optimum sail position is one that maximizes the combined airflow redirected by both the windward and leeward sides of the sail.

The main cause of variation in the force generated by a sail with changes in the sail AOA, is due to variations in the amount of air re-directed due to the Coanda effect on the leeward side of the sail. The Coanda effect is greatest when sailing closest to the wind, but not directly into the wind. The Coanda effect is weakest when sailing with the wind. See Fig. 38 and Fig. 39.

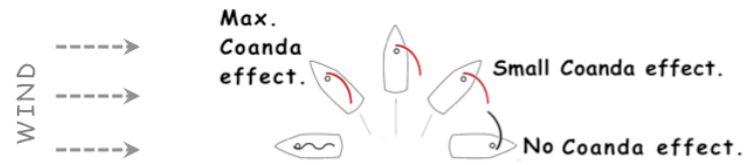

Fig. 38. The Coanda effect and sail AOA.
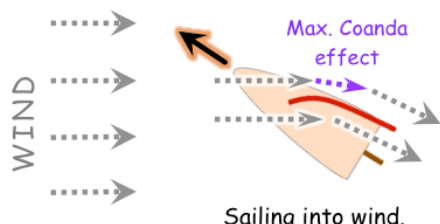

Fig. 39. Coanda effect sailing into and with the wind

\section{Sailing into the wind}

More precisely, sailing closer into the wind with a lower sail AOA allows boats to sail faster because:

i. The Coanda effect on the leeward side of the sail enhances the mass of air re-directed by the sail $(\mathrm{m} / \mathrm{dt})$, as well as its velocity (dv). The Coanda effect is highly sensitive to the sail AOA. On a close haul tack there is less turbulence and airflow separation on the leeward part of the sail. See Fig. 40.
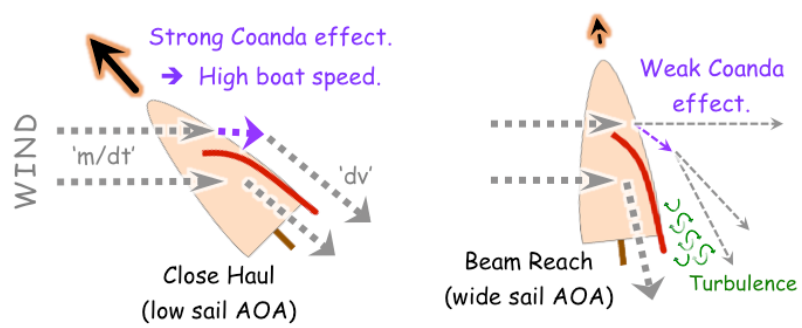

Fig. 40. Coanda effect is stronger on a close haul.

ii. The dynamics of this process creates a positive feedback loop. As the boat sails faster into the wind, this increases the mass of air sailed through each second $(\mathrm{m} / \mathrm{dt})$, further increasing the created forces.

iii. The maximum possible ' $\mathrm{dv}$ ' is limited to the speed of the apparent wind, and ' $\mathrm{dv}$ ' varies over a relatively small range. Therefore, changes in ' $\mathrm{m} / \mathrm{dt}$ ' are relatively more important than changes in ' $\mathrm{dv}$.'

iv. The sailboat heels (tilts) less and moves more efficiently. The apparent wind's force is pushing less sideways against the boat. This means the boat's movement through the water is more efficient, creating less drag, and allowing the boat to sail faster.

In short, turning a sail closer into the wind is similar to pressing down on the accelerator of a car. The sail is more efficient at creating a forward force as it re-directs a greater mass of air each second $(\mathrm{m} / \mathrm{dt})$ at a higher relative velocity (dv).

\section{Sailing directly into the wind}

When sailing directly into the wind (in the irons), the wind pushes the sail relatively flat. Here the sail is not redirecting any wind and no forward force is generated. See Fig. 41.

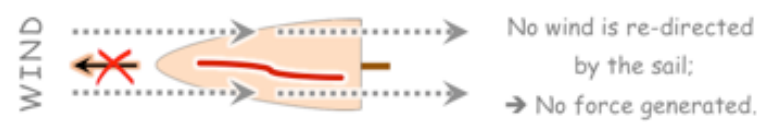

Fig. 41. Sailing directly into the wind.

Hypothetically, a rigid sail could be used to re-direct the wind when the boat's hull is orientated directly into the wind. See Fig. 42.

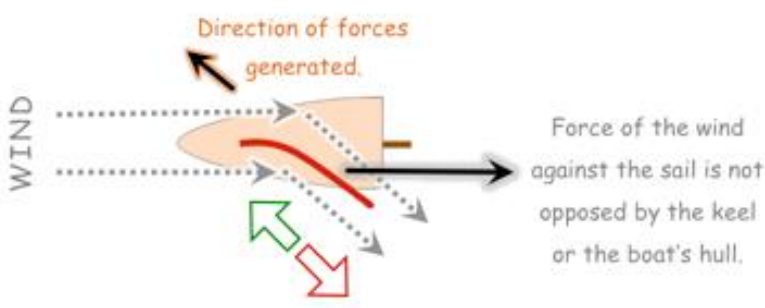

Fig. 42. Sailing directly into the wind with a rigid sail.

However, this configuration is inefficient:

i. The force generated by the sail is not in the direction of travel. The sailboat would be pushed diagonally forward, which creates significantly more drag from the boat's hull in the water. The boat would by crabbing forward.

ii. The keel is aligned into the wind, and therefore, cannot oppose the force of the wind against the sail. In the case of a catamaran, the two hulls of the boat provide no sideways resistance against the wind. For both the boat with a keel and the catamaran, part of the force of the wind that pushes directly against the sail, pushes the boat backwards

\section{E. The Coanda effect and sail shape}

The ideal or optimum sail size and shape depends on the boat's size, dimensions, weight, etc.... and the purpose of the sailboat (eg. racing, v. leisure, etc...).

A lot of equipment is employed while sailing to prevent the sail from losing its shape and thus to maintain the ideal bowed sail shape. This equipment includes batons, reefing points, backstays, etc.

On the leeward side of the sail, the amount of wind redirected (' $\mathrm{m} / \mathrm{dt}$ ), depends primarily on the Coanda effect. In turn this depends mostly on the sail AOA, shape, and height. 
A bowed or concave sail shape enhances the Coanda effect on the leeward side of the sail but reduces the effectiveness of the windward side of the sail. A rigid or flat sail has the reverse effect, which would reduce the wind redirected on the leeward side of the sail, while enhancing the wind re-directed by the windward side of the sail. Therefore, the optimum sail shape is a balance between these two parameters. See Fig. 43.

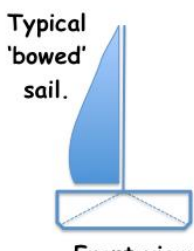

Front view

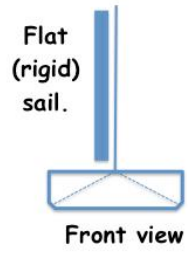

Fig. 43. Different sail shapes.
This paper postulates that the leeward side of the sail can re-directs more wind (displaces more air) than the windward side when sailing into wind for two reasons:

i. The typical 'bowed' shape of a sail enhances the Coanda effect.

ii. The windward side's high-pressure system based on pushing air is less efficient at re-directing wind (displacing air) backwards, as compared to the low-pressure system of the Coanda effect on the leeward side of the sail that pulls air backwards. The Coanda effect has a greater 'reach' and thus affects air a greater distance away from the sail.

\section{EXAMPLE CALCULATION}

\section{A. Overview}

An example calculation of the forward force generated by a sail from a boat sailing into the wind based on Newtonian mechanics and the mass flow rate is provided below.

This example is an approximation and for illustration purposes only, which is intended to demonstrate how Newtonian mechanics can be applied in practice. It is not meant to be precisely accurate nor overly realistic. Nonetheless a more detail and realistic calculation would eventually need to include more accurate assumptions.

\section{B. Assumptions}

The key assumptions include: (See Fig. 44.)

- $\quad$ Standard air density is $1.2 \mathrm{~kg} / \mathrm{m}^{3}$ [1].

- $\quad$ Apparent wind speed $=10 \mathrm{~m} / \mathrm{s}(36 \mathrm{~km} / \mathrm{hr})$

- $\quad$ 'dv' $=8 \mathrm{~m} / \mathrm{s}$ (about $29 \mathrm{~km} / \mathrm{hr}$ )

- The sail is 12 meter vertically high.

- Sail reach is 0.5 meters horizontally either side of the sail, (1.0 $\mathrm{m}$ sail reach in total).
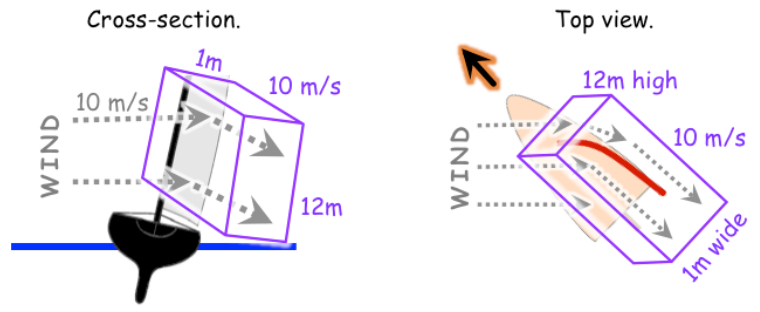

Fig. 44. Sail dimensions.
In this example, for simplicity a number of background assumptions are also made, which do not materially affect the results. It is assumed:

- The sailboat is sailing at constant velocity into a laminar, constant velocity wind, with no water currents. Therefore, the boat is not accelerating.

- The sail airflows that generate a force are assumed to be rectangular in shape. See Fig. 44.

- Vortices or wind shear are not significant.

- The sailboat is assumed to be sailing almost vertically, with little heel (tilt or pitch), which does not affect these calculations.

- The sail width is not considered to be directly relevant to this calculation. It is indirectly important, as it affects the sail reach and the ' $\mathrm{dv}$ ' that is assumed.

There is a difference between the velocity of the apparent wind of $10 \mathrm{~m} / \mathrm{s}$ and the speed at which the re-directed air leaves the sail $(\mathrm{dv})$ at $8 \mathrm{~m} / \mathrm{s}$. This represents the force, energy, and momentum lost to pushing the boat sideways, friction or otherwise.

\section{Example calculation - details}

Methodology: First the volume of air displaced each second by the sail is estimated. Standard air density translates this volume into a mass of air displaced each second $(\mathrm{m} / \mathrm{dt})$. Then taking the assumed ' $\mathrm{dv}$ ', the backwards force can be calculated.

(i) The volume of air displaced by the sail is estimated to be $120 \mathrm{~m}^{3} / \mathrm{s}$, based on the sail height, sail reach, and apparent wind speed.

Volume of air displaced per second

$=$ sail height $\times$ sail reach $\times$ apparent wind speed

$$
120 \mathrm{~m}^{3} / \mathrm{s}=12 \mathrm{~m} \times 1 \mathrm{~m} \times 10 \mathrm{~m} / \mathrm{s}
$$

In other words, a 12 meter vertically high sail with a 1.0 $\mathrm{m}$ sail reach, sailing into a strong $10 \mathrm{~m} / \mathrm{s}(36 \mathrm{~km} / \mathrm{hr})$ apparent wind, will displace a volume of air of $120 \mathrm{~m}^{3} / \mathrm{s}$. See Fig 45.

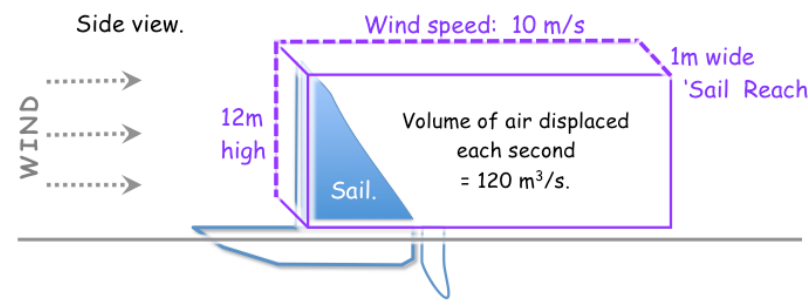

Fig. 45. Volume of air displaced each second.

(ii) The mass of air displaced by the sail each second $(\mathrm{m} / \mathrm{dt})$ is calculated to be $144 \mathrm{~kg} / \mathrm{s}$ based on the volume of air displaced and the standard air density of $1.2 \mathrm{~kg} / \mathrm{m}^{3}$.

$$
\begin{aligned}
\mathrm{m} / \mathrm{dt}= & \text { Volume } / \mathrm{dt} \times \text { Air Density } \\
& 144 \mathrm{~kg} / \mathrm{s}=120 \mathrm{~m}^{3} / \mathrm{s} \times 1.2 \mathrm{~kg} / \mathrm{m}^{3}
\end{aligned}
$$

(iii) The average velocity of the air displaced (dv) by the sail is assumed to be $8 \mathrm{~m} / \mathrm{s}$. This reflects how efficiently the 
sail re-directs apparent wind of $10 \mathrm{~m} / \mathrm{s}$. This is the velocity the airflow leaves the sail to interact with the undisturbed apparent wind, creating turbulence.

$$
\text { 'dv' }=8 \mathrm{~m} / \mathrm{s} .
$$

(iv) The backward force is calculated from multiplying ' $\mathrm{m} / \mathrm{dt}$ ' by 'dv,' using the standard Newtonian equation:

Backward Force $=\mathrm{m} / \mathrm{dt} \times \mathrm{dv}$

$$
\begin{aligned}
& =144 \mathrm{~kg} / \mathrm{s} \times 8 \mathrm{~m} / \mathrm{s} \\
& =1,152 \mathrm{~kg} \mathrm{~m} / \mathrm{s}^{2} \\
& =1,152 \mathrm{~N}
\end{aligned}
$$

This generates and equal and opposite forward force of $1,152 \mathrm{~N}$, as shown by the equations:

$$
\begin{aligned}
\text { Forward Force } & =\text { Backward Force } \\
& =1,152 \mathrm{~N}
\end{aligned}
$$

\section{Summary}

In summary, an example calculation assumes that a $12 \mathrm{~m}$ high sail re-directs the wind $0.5 \mathrm{~m}$ on either side of the sail (1.0 $\mathrm{m}$ in total). In an apparent wind blowing at $10 \mathrm{~m} / \mathrm{s}$ with a standard air density of $1.2 \mathrm{~kg} / \mathrm{m}^{3}$, the sail displaces $144 \mathrm{~kg} / \mathrm{s}$ of air $(\mathrm{m} / \mathrm{dt})$.

The wind is re-directed by the sail at $8 \mathrm{~m} / \mathrm{s}(\mathrm{dv})$; therefore, according to Newtonian mechanics this would create a backward force of $1,152 \mathrm{~N}$. The reaction generates an equal and opposite forward force of 1,152 N. See Fig. 46.

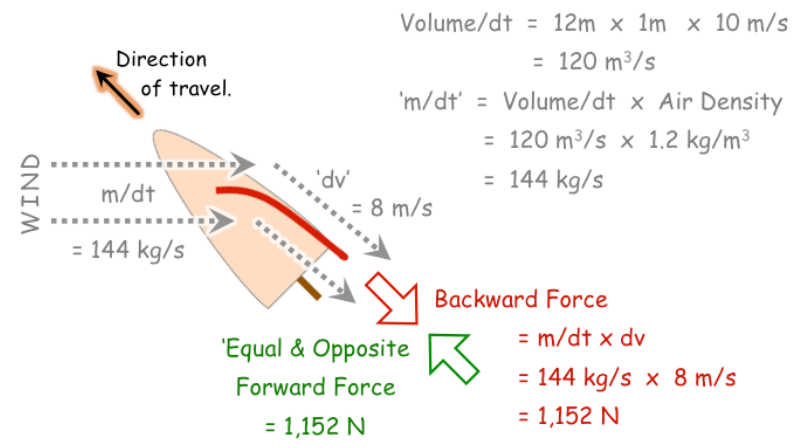

Fig. 46. Example calculation of Newtonian forces.

This example calculation shows how simple the forces involved are.

The key parameters that are the most difficult to estimate in practice are the 'sail reach' and 'dv.' Also, these assumptions are relatively the most speculative in this example calculation.

Other theories of sailing, such as fluid mechanics and vector-based approaches, fail to provide simple example calculations based on realistic conditions.

\section{A SAILING CONUNDRUM SOLVED}

\section{A. Sailing into / with the wind}

When sailing with the wind, the wind pushes the sail and the boat downwind. However, when sailing into the wind, the sail re-directs apparent wind backwards to generate a forward force. See Fig. 47.

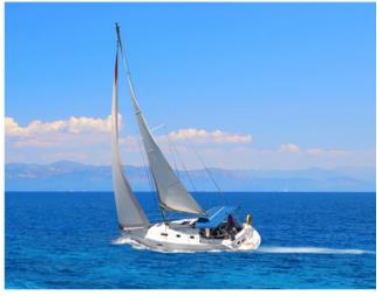

Sailing into wind - close haul.

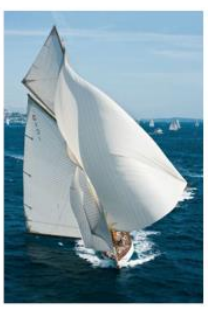

Sailing with. the wind
Fig. 47. Boats sailing into and with the wind.

\section{B. Conundrum described}

A sailboat on a close-haul can sail into the wind faster than the wind itself. However, a boat sailing with the wind cannot sail faster than the wind. Many people claim that a boat can sail several multiples faster than the wind speed, which is certainly true for sailboats with hydrofoils. On the other hand, a boat cannot sail directly into the wind (in the irons). See Fig. 48.
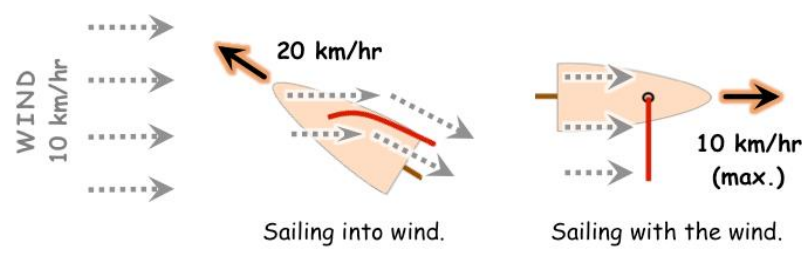

Sailing with the wind

Fig. 48. Example of sailing speeds relative to the wind.

This is a conundrum for several reasons:

i. At first glance it appears illogical for a boat to be able to sail into the wind and do so faster than the wind itself. Surely the wind should blow the boat in the direction of the wind. How then does a sailboat use the wind to create a force in the opposite direction that is greater than the wind?

ii. The amount of sail area that is directly exposed to the wind does not determine the force generated by the sail. For example, on a close haul relatively little sail is exposed to the wind but a lot of force is generated, as compared to sailing with the wind.

\section{The conundrum explained}

Newtonian mechanics and the Coanda effect provide a simple solution to this conundrum.

i. When sailing into the wind, a significantly greater airflow (m/dt) is re-directed due to the Coanda effect on the leeward side of the sail at a higher velocity (dv).

The increase in airflow on the leeward side of the sail more than offsets any reduced effectiveness of the windward side of the sail that has less sail exposed to the wind.

ii. When running with the wind, the sail has nothing to push against and cannot re-direct any wind. No 'equal and opposite force is generated. Therefore, the boat's speed is limited to the speed of the wind. In addition, no Coanda effect is generated on the leeward part of the sail, limiting the amount of wind re-directed. Only the windward side of the sail is providing any forward force. See Fig. 49. 


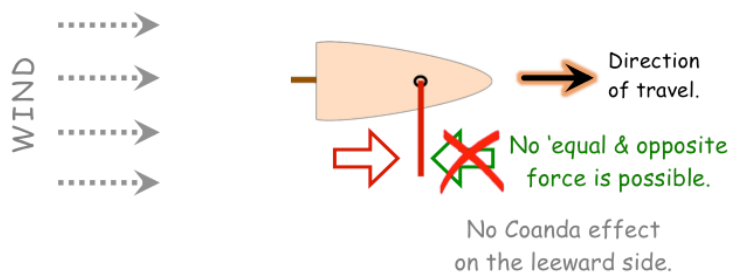

Fig. 49. Sailing with the wind.

\section{Other explanations}

The Newtonian solution of sailing into wind to the conundrum is consistent with other pundits' views. For example: "For sailing downwind, one wants fairly square sails, which are best at catching the wind. But for sailing upwind, taller narrower sails are best, .....” [3] See Fig 47. and Fig 48.

According to Newtonian mechanics:

Boats with tall narrow sails have a long mast area exposed to the wind in the direction of travel, which maximizes ' $\mathrm{m} / \mathrm{dt}$ ' due to the Coanda effect on the leeward side. This principle is similar to how why albatrosses and gliders have long narrow wings with high aspect ratios. This wing design maximizes the airflow displaced $(\mathrm{m} / \mathrm{dt})$ due to the Coanda effect [12], [15]. In turn, this allows the albatross or glider to soar into the wind, gaining altitude and airspeed, imilar to a boat sailing into the wind [13].

On the other hand, square sails maximize the wind caught by the windward side. In this case, this boat performs best sailing downwind, where there is no Coanda effect.

Currently, no other theory of sailing can adequately explain this conundrum.

\section{ADDITIONAL ANALYSIS}

\section{A. Multiple sails}

This Newtonian based analysis helps explain why multiple sails (e.g. jib and mainsheet) provide a greater forward force than one large sail, even though the total sail size is the same.

Multiple sails increase the mass flow rate $(\mathrm{m} / \mathrm{dt})$ without significantly jeopardizing the relative acceleration of the air (dv). For example, a boat with two sails has two leading edges facing the wind, which increase the effective sail reach.

This effect increases the overall force generated using the Newtonian equation: Force $=\mathrm{ma}=\mathrm{m} / \mathrm{dt} \mathrm{x} \mathrm{dv}$. In this case, the total sail size is the same for the boat with multiple sails as the boat with one sail. See Fig. 50 and 51.
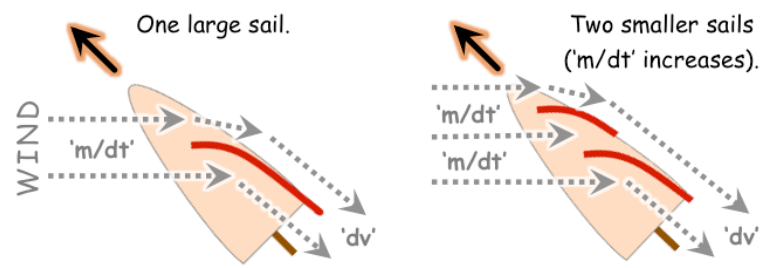

Fig. 50. One large sail v. two sails (mainsheet and jib).
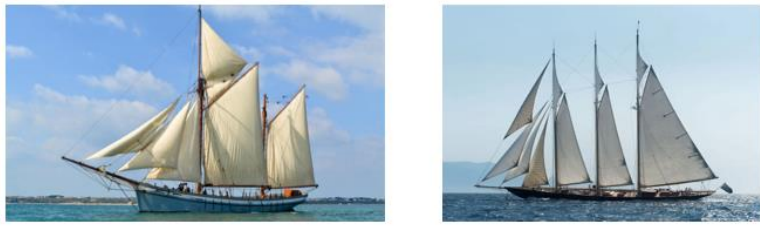

Fig. 51. Boats with multiple sails [6].

To put it another way, a sail's ' $d v$ ' is limited to the speed of the apparent wind. Therefore, to maximize the forward force generated, a sailboat has no choice but to maximize ' $\mathrm{m} / \mathrm{dt}$.' One way of doing this is to increase the number of sails.

The drawback to more sails is increased drag from the additional masts. There is a trade-off between increased ' $\mathrm{m} / \mathrm{dt}$ ' and increased drag from additional sails.

Also, the physical environment of a boat limits how many sails it can have. Larger boats tended to have more sails.

In principle, additional sails on a boat are similar to the physics for additional wings on an airplane.

Overlapping sails will affect the airflows and consequently the forces involved. However, this aspect of sailing is beyond the scope of this paper.

\section{B. Apparent Wind Velocity ${ }^{2} \Leftrightarrow$ Forward Force}

At a constant boat speed (so, no acceleration), drag from the boats and the sails equals the forward force generated by the sails. This dynamic can be expressed using the standard equation for drag: [1]

Forward Force

$$
\begin{aligned}
& =\text { Drag SAILS } \\
& =0.5 \text { (Velocity }^{2} \text { x Air Density x Surface Area } \times \\
& \text { Coefficient of Drag SAILs) }
\end{aligned}
$$

where:

Velocity = Velocity of the apparent wind;

Surface Area $=$ Surface area of the boat and sail exposed to the direction of the wind.

This analysis implies that the forward force generated by a sail is proportional to the square of the velocity of the apparent wind. If the apparent wind's velocity doubles, then the drag quadruples, and the forward force also quadruples. See Fig. 52.

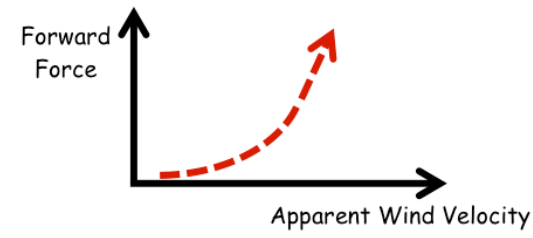

Fig. 52. Apparent Wind Velocity $\Leftrightarrow$ Forward Force

Newtonian mechanics (i.e. Force $=\mathrm{m} / \mathrm{dt} \times \mathrm{dv}$ ) can be applied to explain this relationship:

An apparent wind blowing twice as fast will double the mass of air each second $(2 \mathrm{x} \mathrm{m} / \mathrm{dt})$ that passes the sail.

The wind is accelerated relative to the boat twice as fast as before $(2 \mathrm{x} \mathrm{dv})$. 
The combined effect of these two actions quadruples the backward force each second $(4 \mathrm{x}$ Force $=2 \mathrm{~m} / \mathrm{dt} \times 2 \mathrm{dv})$. In turn, this quadruples the equal and opposite forward force generated. See Fig. 53.

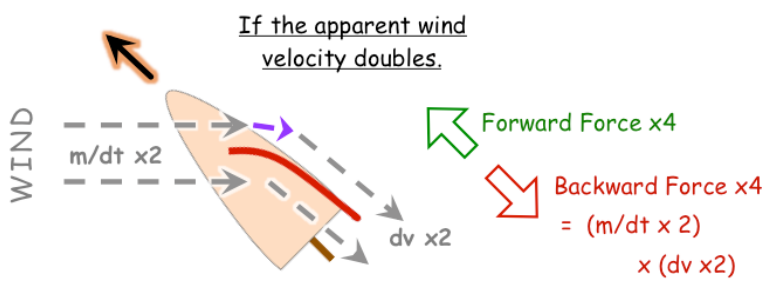

Fig. 53. Force $\mathrm{x} 4=(\mathrm{m} / \mathrm{dt} \mathrm{x} 2) \times(\mathrm{dv} \times 2)$

\section{Momentum, kinetic energy, and power}

Mass, momentum, and energy is transferred from the wind to the sail, to power the boat forward. There is no net gain or loss of mass, momentum, and energy in this process.

If the apparent wind's velocity doubles then its momentum also increases (momentum $=$ mass $\times$ velocity) . This aspect enables the wind to push the boat forward faster.

In addition, the analysis above is supported by the calculation of the kinetic energy produced by the sail to push the boat forwards. The standard equation for kinetic energy:

$$
\text { Kinetic Energy (K.E.) }=.5 \mathrm{mv}^{2} \quad[1]
$$

where:

$\mathrm{m}=$ Mass of air re-directed by the sail to generate a force. $\mathrm{v}=$ Velocity of this mass of air re-directed by the sail.

The kinetic energy of the apparent wind is proportional to its velocity squared. Therefore, if the apparent wind's velocity doubles its kinetic energy quadruples. In turn this helps to explain why a boat's velocity increases in a nonlinear manner with increased wind speed.

The power generated by the sail can then be calculated based on the amount of energy transferred from the wind to the boat, per unit time. These units are consistent with those units used to calculate the forces involved using Newtonian mechanics (mass and velocity of the wind). See Fig. 54.

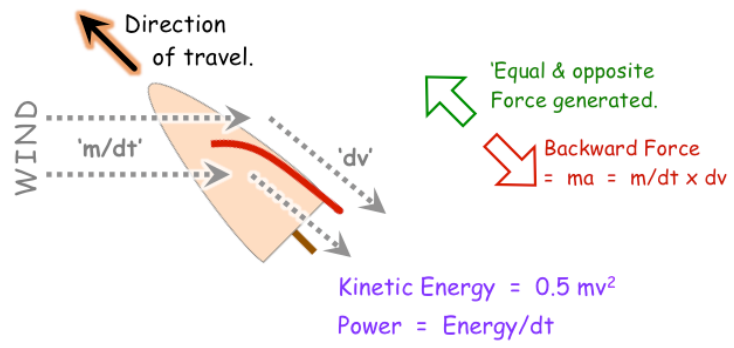

Fig. 54. Force, kinetic energy and power from a sail.

No other theory of sailing provides such an accurate and simple method to calculate the forces, kinetic energy and power generated by a sail.

\section{Water currents and drift}

This paper considers the speed and direction of any moving water relative to the boat as irrelevant to the forward force and power generated by the sail. The main effect of any water current is to cause the boat to drift by pushing against the boat's hull and keel. Casual observations while sailing confirm this assertion. See Fig. 55

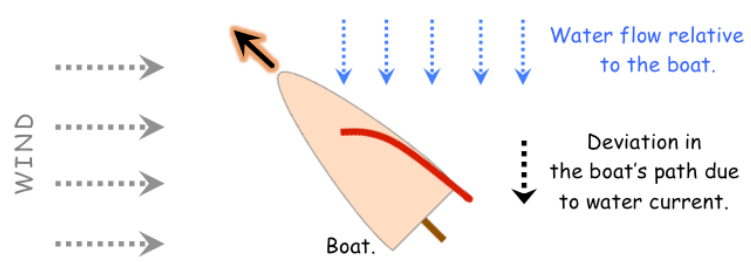

Fig. 55. Drift due to water current.

\section{E. The forces created by a rudder}

The same Newtonian principles apply to how a rudder is used to steer a boat. For a sailboat that is moving forwards, changing the AOA of the rudder re-directs water flow under the boat. This action creates a force based on the mass of water re-directed each second and the relative velocity of the water flow. The reaction generates an equal and opposite force, which pushes the stern (rear) of the boat in the direction caused by these forces. The stern of the boat is simply pivoted around the boat's center of gravity. See Fig. 56.

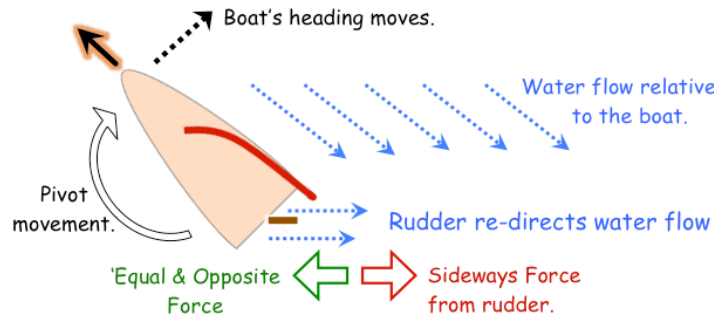

Fig. 56. Rudder re-directs water flow.

\section{$F$. Vortices and wind shear}

This analysis does not account for vortices or wind shear created by the sail. Contrary to the views of some nautical experts, these are relatively small and unimportant to the forward force created. They can be important to a sail's performance, but not of primary importance.

\section{COMParison to Wings}

\section{A. Comparison to airplane wings and lift [12]}

The physics of sailing is frequently compared to the physics of how airplane wings generate lift. They have similar shapes and designs and are considered to involve similar airflows moving around airfoils (wings / sails) to produce forces that enable movement.

However, it is more accurate to say that a wing (airfoil) and hydrofoil have similar designs and functions that generate similar fluid flows and forces, which are somewhat different to those of a sail. It is wrong to say that how wings 
generate lift is the same as how sails propel boats forward, because the airflows and forces are different.

The principles of physics (Newtonian mechanics) that explain lift from a wing and sailing are similar but are applied differently as the airflows differ. Therefore, sails and wings can be compared to a limited extent.

It would be inconsistent to propose that fluid mechanics can explain the lift by airplane wings while Newtonian mechanics explains how boats sail into the wind, or vice versa. Either Newtonian mechanics explains both, as claimed by this paper, or fluid mechanics does.

$$
\text { B. Lift }=m / d t \times d v[12]
$$

For reference, a brief summary of how an airplane generates lift according to Newtonian mechanics based on the mass flow rate is provided below.

In stable cruise flight, wings with a positive angle of attack (AOA) fly through a mass of air each second $(\mathrm{m} / \mathrm{dt})$, and accelerate this air to a velocity (dv) downwards and slightly forwards. This action creates a downward force due to Newtons 2nd law of motion (i.e. Force $=\mathrm{ma}=\mathrm{m} / \mathrm{dt} \quad \mathrm{x}$ $\mathrm{dv})$. This is summarized by the following equations:

$$
\begin{aligned}
& \quad \text { Force }_{\text {DOWN }}=m a=m / d t \times d v \\
& (8) \\
& \text { Force }_{\text {DoWN }}=\text { Force }_{U P}(\text { Lift }) \\
& \Rightarrow \quad \text { Lift }=m / d t \times d v
\end{aligned}
$$

The 'equal and opposite' upward force generated due to Newtons 3rd law of motion, pushes the airplane up and provides lift. Lift is the vertical component of the upward force. It's simple; air goes down and the airplane goes up. See Fig. 57 and Fig. 58.

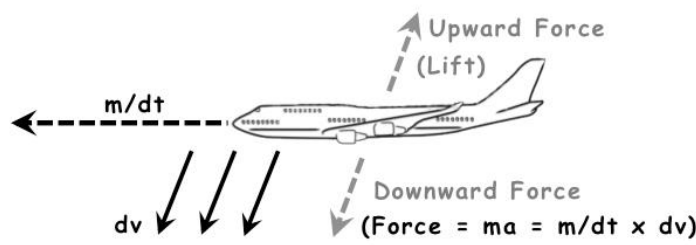

Fig. 57. Newtonian forces on an airplane.

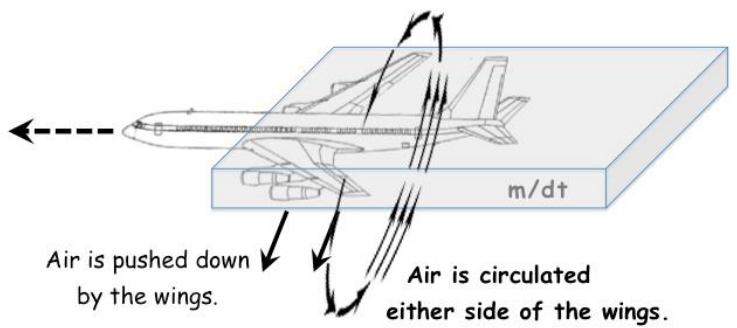

Fig. 58. Forces on an airplane $-3 \mathrm{D}$ view.

Wings circulate the air flown through; while sails do not. The air flown through and displaced down by the wings, pushes air up elsewhere to replace the space vacated by the air displaced down. This circulates the air. See Fig. 59.

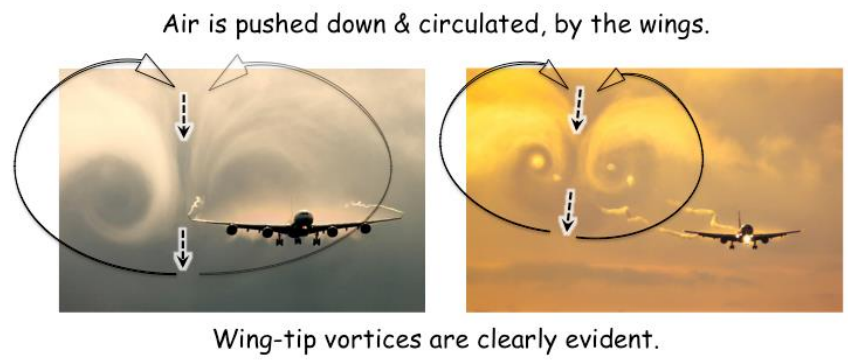

Fig. 59. Photographs of airliners flying in clouds [11].

Evidence for air being pushed down by airplanes in flight (downwash), is available from videos of ultra-low flying fighter jets disrupting dust on the ground and from jets flying through clouds. See Fig. 60.
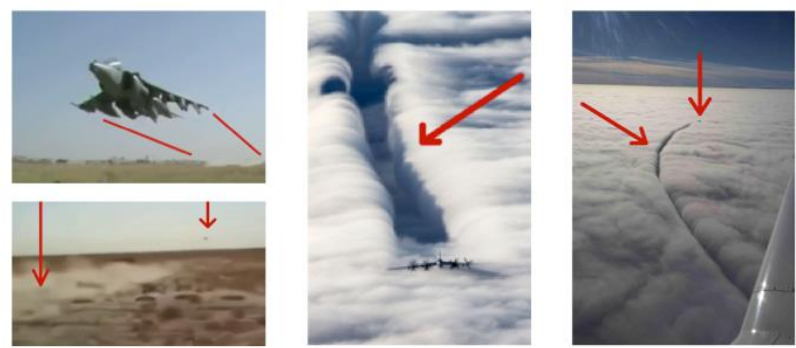

Fig. 60. Evidence of downwash.

\section{Wing and sail airflows and forces are different.}

It is more accurate to say that a wing (airfoil) and hydrofoil have similar designs and functions that generate similar fluid flows and forces, which are somewhat different to those of a sail.

It is wrong to say that how wings generate lift is the same as how sails propel boats forward, because the airflows and forces are different:

- A moving wing is aligned in the horizontal direction, to generate vertical lift against gravity. The wing moves through static air, as the engines drive the airplane forwards.

Wings circulate the air flown through to generate a force. Whereas, sails do not circulate the air passed through, but create turbulence instead.

- A sail is aligned in the vertical direction and generates forward motion from a moving wind. A sail redirects airflow backwards to push the boat forward, while a wing displaces air down and the airplane up against gravity. See Fig. 61.
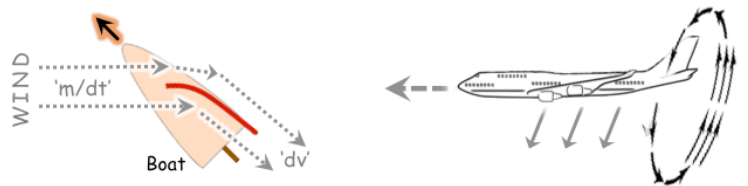

Fig. 61. Airflows on a sailboat and an airplane wing. 
If a sail did generate force similar to a wing, it would push the boat sideways. See Fig. 62 .
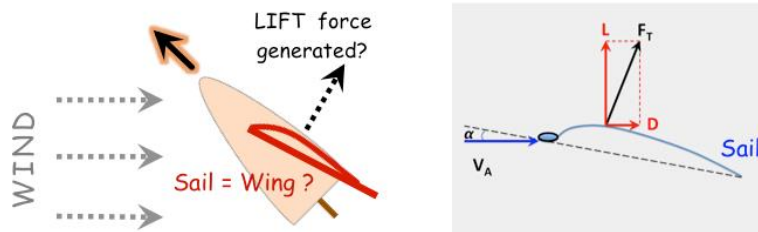

Fig. 62. Sail = wing? Vector forces [7].

Therefore, when analyzing the forces resulting from the movement of the sail/wing and air relative to each other, it is critical to remember which is static and which is moving.

\section{FluID MEChanICS AND SAILING}

\section{A. Fluid mechanics}

Some academics promote theories to explain the physics of sailing into the wind based on hydronamics (fluid flow) [1], [3], [4], involving complex mathematical equations (e.g. Navier-Stokes). These theories are devoid of empirical evidence and proof, and are frequently presented without any example calculations. Worse, many academics mistake mathematical proof or computer simulations, such as Computational Fluid Dynamics (CFD) for scientific proof. See Fig. 63.

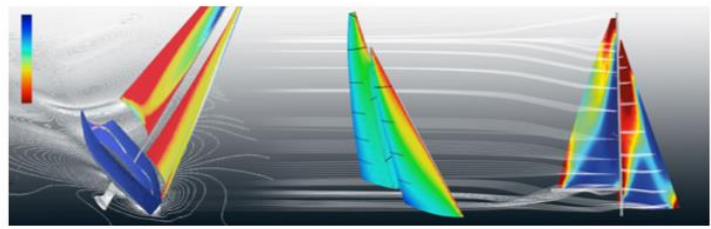

Fig. 63. Airflow simulations on a sail.

Problems with fluid mechanics include:

- There is no one equation agreed upon by the experts. For example, there are numerous variations of the NavierStokes equations (e.g. Euler equations).

No agreement on whether sails are pulled forward due to air friction, air viscosity or low air pressure.

- There is no conclusive experimental proof for any one specific equation or explanation.

Advocates of fluid mechanics frequently defend the use of fluid flow to explain sailing based on the assumption that fluid flow can explain lift by airplane wings, as sails are similar to wings. This is a logical fallacy, as fluid mechanics also fails to explain lift by airplane wings [14].

In summary, fluid mechanics is useful for analyzing airflows around a sail, but it is unable to explain the forces pushing the boat forwards. Although, airflow and force are related, they are separate concepts.

\section{B. Are sailboats pulled (sucked) forwards?}

Some pundits believe that boats sailing into the wind are sucked (pulled) forwards by low air pressure at the front of the sail [3]. See Fig. 64.

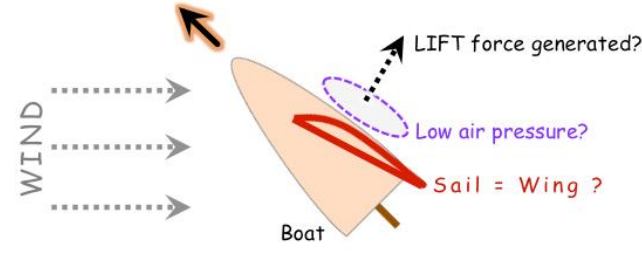

Fig. 64. A sailboat is pulled (sucked) forward?

These theories based on low air pressure pulling the sailboat forward can easily be shown to be false:

- This theory is illogical because if significant low air pressure arose on the front of the sail, then this low pressure would simply pull the air in front of the boat backwards. Low pressure would not pull the heavy boat forwards through the water, as this would be harder to do and require more energy.

- Low air pressure in front of the sail is a consequence of motion, not a cause.

- Almost no animals or objects propel themselves forward by low air pressure in front of them. Objects and animals move primarily by first pushing backwards, to generate an equal and opposite forward force.

- The telltales on the leeward side of the sail are always pushed backwards, in the same direction that the re-directed wind (except in the case of turbulent airflow). If low pressure were pulling the boat forward, then the telltales would be facing forward. This does not happen (the telltales always face backwards). See Fig. 65.
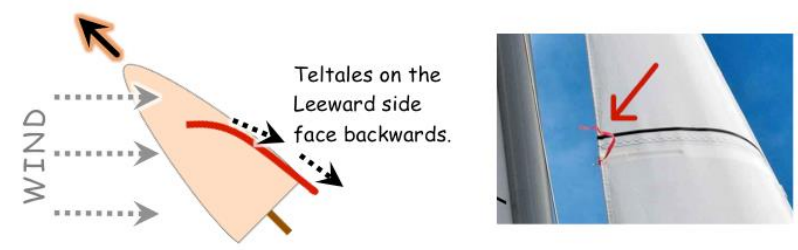

Fig. 65. Telltales face backwards.

\section{DISCUSSION OF RESUlTS}

\section{A. Newtonian mechanics explains sailing}

It should not be surprising that Newtonian mechanics and the Coanda effect can explain the physics of sailing into the wind, as shown in Fig. 66.

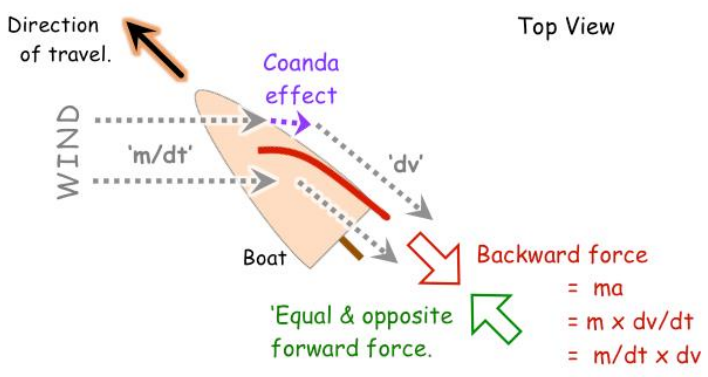

Fig. 66. Forces acting on a sailboat on a close haul tack.

This approach provides a new and simple method to estimate the force generated by a sail. There is no need for complex equations, like Navier-Stokes, which rely on fluid 
mechanics. Fluid mechanics explains the airflows created but does not explain the resultant forces.

This approach also provides a method to more accurately calculate kinetic energy and power generated by a sail, using the same parameters as the Newtonian explanation of sailing into the wind. Fluid mechanics cannot provide this analysis of energy and power.

All practical aspects of sailing, such as sail size and shape, can be analyzed in terms of the impact they have on ' $\mathrm{m} / \mathrm{dt}$ ' and ' $\mathrm{dv}$ ' and thus the generated force.

Specifically, this Newtonian approach with the Coanda effect can explain several conundrums, including:

- How a boat's speed increases when sailing closer into the wind, despite having less sail area exposed to the wind.

How a boat can sail into the wind faster than the wind itself, but a boat cannot sail with the wind at a speed that is faster than the wind.

- Why boats sail better with multiple sails, instead of one large sail with the same total sail area.

This Newtonian explanation of sailing based on the mass flow rate is consistent with the Newtonian explanation for how airplanes generate lift [12] and dynamic soaring performed by albatrosses [13]. The same basic principles of physics apply universally, but how they apply varies.

This insight into the physics of sailing is extremely significant as it is fundamental to sailing and the reputation of the sport. It would allow for better sailboats and sails to be designed and would allow ultimately for more efficient sailing. Currently resources are being wasted pursuing false theories and sub-optimal designs.

\section{B. Comment}

Given that the physics of how boats float can be explained as simply as Archimedes did over 2,000 years ago. Then it should not be surprising that the physics of sailing into the wind should be equally as simple to explain, as proposed by Newtonian mechanics.

It is puzzling why it has it taken so long (more than 500 years) for the physics of sailing to be correctly explained using Newtonian mechanics.

More analysis and research are needed to fully understand and quantify this explanation. For example, analysis needs to be done to better measure and understand how sail reach alters with changes in sail AOA and sail shape.

\section{CONCLUSIONS}

Newtonian mechanics based on mass flow rate explains the physics for how boats sail into the wind and is consistent with what is observed. This explanation provides a simple way to describe and calculate the force generated by a sail.

\section{DISCLAIMER}

The author confirms that all data in the manuscript are authentic, there are no conflicts of interest, and all sources of data used in the paper are acknowledged (except where the correct source could not be identified).

\section{FUNDING}

This paper was self-funded by the author.

\section{REFERENCES}

[1] NASA, Glenn Research Centre. www.grc.nasa.gov.

[2] W. Püschl, High-speed sailing, Published 8 May 2018, European Physical Society, European Journal of Physics, Volume 39, Number 4.

[3] B. Anderson, The physics of sailing into the wind, Physics Today Magazine, Feb 2008. Volume 61, Issue 2, Page 38, DOI: $10.1063 / 1.2883908$

https://physicstoday.scitation.org/doi/10.1063/1.2883908

[4] R.M. Wilson, The Physics of Sailing, JILA and Department of Physics, University of Colorado, USA, February 7, 2010.

[5] N.F. Smith (1972); Bernoulli and Newton in Fluid Mechanics, the Physics Teacher Journal, (AAPT), volume 10; Published online in 2006 at: https://doi.org/10.1119/1.2352317.

[6] R. Crowley 2015, Conquerors: How Portugal Forged the First Global Empire. Random House Publishing, ISBN-10: 0812994000; ISBN-13 : 978-0812994001

[7] Wikiwand, https://www.wikiwand.com/en/Forces_on_sails.

[8] Flickr, António Alfarroba, 24 August 2020, caravela carave; https://www.flickr.com/photos/alfarroba/14664349019.

[9] Image: https://astrofella.wordpress.com/2018/07/06/conquerorsroger-crowley/.

[10] Fraser yachts. www.fraseryachts.com.

[11] Sources: http://i.stack.imgur.com/cyr0c.jpg; Bernal Saborio, https://www.flickr.com/photos/44073224@N04/.

[12] N. Landell-Mills (2019), Newton explains lift; Buoyancy explains flight. The physics of how airplanes stay airborne. Pre-Print DOI 10.13140/RG.2.2.16863.82084.

[13] N. Landell-Mills (2019), Newton and the Coanda effect explain dynamic soaring; Pre-Print DOI:10.13140/RG.2.2.29669.55527

[14] N. Landell-Mills (2019), How airplanes generate lift is disputed (Newton v. Fluid Mechanics). Pre-Print DOI: 10.13140/RG.2.2.34380.36487

[15] N Landell-Mills (2019), Newtonian mechanics explains how wing design affects lift (glider v. fighter jet); Pre-Print DOI 10.13140/RG.2.2.20216.80647.

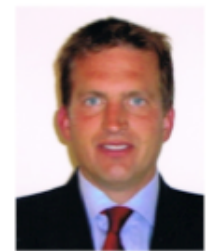

The author is a British citizen and was born in 1966 in Botswana.

The author is a graduate of the Dept. of Humanities \& Social Sciences, The University of Edinburgh, Edinburgh, UK. He was awarded a M.A. degree class 2:1 in economics and economic history in 1989. He qualified as an accountant (ACA) in 1993 and as a chartered financial analyst (CFA) in 2006. He was a member of the HAC in the UK army reserves 1990-7; where he was trained by the Special Forces He is slightly dyslexic.

The author worked in finance and telecoms $1990-2012$. He has been an independent researcher since 2015, based in Chamonix, France. He was has a strong interest in the physics, specializing in airflow and aerodynamics and lift. He has written 20 papers on in this subject (5 published and 15 unpublished), which are available on the website: www.researchgate.net. He was a private pilot (PPL) and maintained his own 'home-built' singleengine aircraft (reg: G-OSJN; a Europa XS monowheel).

Author Contributions: This paper is entirely the work of the author, $\mathrm{Mr}$ Nicholas Landell-Mills. 